\title{
超低频脉冲磁场抑制癌瘤和提高细胞 免疫功能的实验研究
}

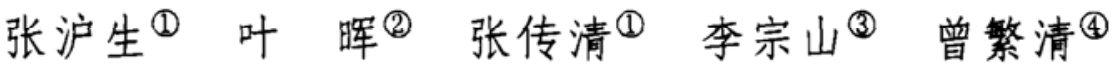 \\ 杜 碧( 张晴川 ${ }^{(5)}$ 黄兴鼎 ( 陈柳林 ${ }^{(0)}$
}

(11武汉大学物理系, 武汉 430072; (2)华中理工大学生物工程系, 武汉 430074; (3)湖北医科大学, 武汉 430071; (4)武汉大学分析测试中心, 武汉 430072; (5)武汉大学生命科学学院, 武汉 430072;

(6)湖北省中医学院附風医院, 武汉 430061)

\begin{abstract}
摛要在报道用电子显微镜观测超低频脉冲磁场（峰值磁场 $0.6 \sim 2.0 \mathrm{~T}$, 磁场梯 度 $10 \sim 100 \mathrm{~T} \cdot \mathrm{m}^{-1}$, 脉冲宽度 $20 \sim 200 \mathrm{~ms}$, 重复频率 $0.16 \sim 1.34 \mathrm{~Hz}$ ) 抑制鼠 S-180 肉 瘤和加强免疫细胞溶癌作用以后, 报道了用 Faulgen 染色法测定肉瘦细胞核的 DNA 倍性,和用电镜技术和细胞结构的体视学分析磁场对癌细胞形态的影响, 观测到磁场 影响癌细胞的代谢: 磁场使癌细胞的恶性程度降低, 抑制其高速和异形生长; 磁场抑 制癌细胞的分裂和 DNA 的复制; 磁场提高细胞免疫功能, 加强淋巴细胞、浆细胞反 应。
\end{abstract}

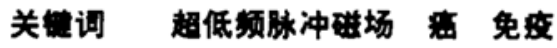

地球的磁场 (大小约 $0.05 \mathrm{mT}$ ) 和地球上生物的生命活动密切相关 ${ }^{[1]}$. 国内外不少人研究 磁场的生物效应, 从 1961 年举行以磁场生物效应为主的国际生物磁学会议. 磁场对离体培养 的癌细胞的作用有较多的报道. Halpern 等观测到 $0.12 \mathrm{~T}$ 的磁场对子宫颈癌细胞的生长无影 响. ${ }^{[2]}$ Mulay 等观测到 S-37 肉㿔细胞被 $0.4 \mathrm{~T}$ 的磁场杀死 ${ }^{[3]}$. 张小云等观测到峰值 $12 \sim 15$ T、脉宽 $32 \mathrm{~ms}$ 的脉冲磁场能杀死子宫颈和悬咽癌细胞 ${ }^{[4]}$. 磁场抑制㿋细胞的动物实验和应 用磁场治癌的报道也不少见. 常汉英等用峰值 $0.8 \mathrm{~T}$ 、脉宽 $22 \mathrm{~ms}$ 的脉冲磁场可抑制鼠 S-180 肉瘤 ${ }^{[5]}$, 并用上述脉冲磁场治疗中晩期癌症患者 18 例, 其中显效 9 例, 有效 9 例 ${ }^{[6]}$. 瑞典医生 Wollin 从 1987 年起用 Nd-Fe-B 永磁体 (表面磁场 $0.4 \mathrm{~T}$ ) 治疗 50 名瑞典和美国癌症患者均有 效 ${ }^{[7]}$. 我们报道了用电镜观测超低频脉冲磁场不仅可抑制鼠 S-180 肉瘤, 而且能提高免疫细 胞的功能, 加强免疫细胞的溶癌作用 ${ }^{[8]}$. 我们还用上述脉冲磁场在广州军区武汉总医院肿瘤 科治疗中晚期癌症患者 6 例, 其中显效 4 例, 有效 2 例 ${ }^{[9]}$.

由于超低频脉冲磁场能抑制癌瘤和提高细胞免疫功能, 所以它可能成为一种辅助治疗癌 症的新方法.

\section{1 材料与方法}

取年龄 (2 个月)和体重 $(36 \sim 40 \mathrm{~g})$ 相近的昆明小白鼠 24 只, 雌雄不限, 随机分成 2 组, 
$1 \sim 12$ 号为治疗组, $13 \sim 24$ 号为对照组. 由武汉同济医科大学基础医学院生物室, 用 S-180 肉 瘤细胞腹水液对 24 只小白鼠接种, 皮下注射到鼠右前肢下方, $4 \sim 5 \mathrm{~d}$ 以后有㾇长出.

将治疗组鼠放在有气孔的有机玻璃盒内, 并把盒置于自行设计的超低频脉冲磁场发生器 的直径为 $10 \mathrm{~cm}$ 的磁头上. 当磁头的线圈中有脉冲电流通过时, 就产生脉冲磁场, 其参数值: 峰值磁场为 $0.6 \sim 2.0 \mathrm{~T}$, 磁场梯度为 $10 \sim 100 \mathrm{~T} \cdot \mathrm{m}^{-1}$, 脉冲宽度为 $20 \sim 200 \mathrm{~ms}$, 重复频率为 $0.16 \sim 1.34 \mathrm{~Hz}$. 每天对治疗组鼠治疗 1 次, 每次 $15 \mathrm{~min}$, 对照组鼠不给治疗. $28 \mathrm{~d}$ 以后将鼠 都拉断颈椎处死, 取出肉瘤, 称瘤重. 取瘤组织, 制备样品, 分别采用光学和电子显微镜观察, Faulgen 染色法测定癌细胞核 DNA 倍性, 细胞结构的体枧学分析癌细胞及其核的形态.

\section{1 光学显微镜制样和观寀}

取 $1 \mathrm{~cm}^{3}$ 左右鼠肉瘤组织, $10 \%$ 福尔马林室温固定, 酒精梯度脱水, 二甲苯透明, $60{ }^{\circ} \mathrm{C}$ 温箱 中浸蜡, 室温下石蜡包埋. 切片厚度为 $3 \sim 4 \mu \mathrm{m}, \mathrm{HE}$ 染色. 光镜观察的高倍为 300 倍, 低倍为 100 倍.

\section{2 透射电镜(TEM)制样和观察}

取肉㾇组织约 $1 \mathrm{~mm}^{3}$, 经过前固定、缓冲、后固定、脱水、浸透、包埋后, 超薄切片, 厚度约为 $50 \mathrm{~nm}$, 醋酸铀、柠檬酸铅双染色. 用日产 HV-11A 型透射电镜观家, 加速电压为 $50 \mathrm{kV}$.

\subsection{Faulgen 染色法测定柿 DNA 倍性}

以光镜的包埋块切片; 再二甲苯透明, 酒精梯度脱水; $5 \mathrm{~mol} / \mathrm{L}$ 的 $\mathrm{HCl}$ 中酸水解 $40 \mathrm{~min}$; 蒸 馏水冲洗, Schiff 试剂作用 $1 \mathrm{~h}$ 后再冲洗; 脱水、透明、封片. 用医学图象处理系统 TJTY-300 做核 DNA 倍性测定. 图象由光镜 $(\times 40)$ 选择视野, 经摄像机传入图象分析系统内, 由其对细 胞核自动分割和测量. 每张切片随机选择 3 个以上的枧野, 每个枧野的测量核数超过 20 个. 由计算机系统统计原始数据, 给出结果和进行 2 组样本间差异的显著性分析, 由系统自动打印 出各项参数.

\section{4 细胞结构的体视学分析肉演细胞及柿的形态}

细胞形态的定量分析, 采用电镜技术和体枧学相结合的方法 ${ }^{[10]}$. 实验每组取 4 个组织 块, 每块切片后满在 2 个铜网上. 电镜下选择用结构清晰、反差明显的铜网拍照. 每组选择测 量的细胞大于 20 个, 且主要选形态较正常的细胞群. 照片倍率选 $1200 \sim 1500$ 倍, 光学放大 4 倍. 用正方测试板覆盖在电镜照片上计数.

\section{2 实验结果}

\section{1 肉眼观寀}

治疗组的瘤体较小、较硬, 局限易剥离, 可见表面有粘膜包窔, 与周围组织分界清楚, 横切 面呈灰红色. 对照组的瘪体较大、较软, 离散呈菜花状, 难剥离, 未见明显包膜, 与邻近正常组 织连接紧密, 横切面呈灰红色, 见图 1 和 2 .

\section{2 远射电镜( TEM) 观宗结果}

经磁场治疗后, 肉瘦细胞核膜比较光滑, 内质网和线粒体由正常变成肿胀, 肉瘦内微血管 减少且血管中红细胞萎缩; 免疫细胞溶痛作用显著. 而对照组肉瘤细胞的内质网和线粒体分 化形态较完全, 有的核形异常, 见图 3 5. 


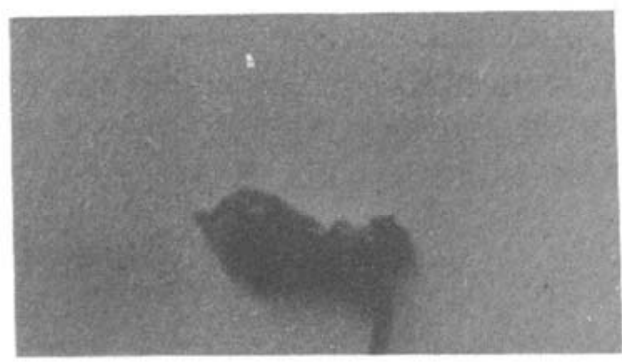

图 1 治疗组 6 号肉眼观察照片 $0.4 \mathrm{~g}$ 较结实, 有粘膜包围 $(\times 0.2)$

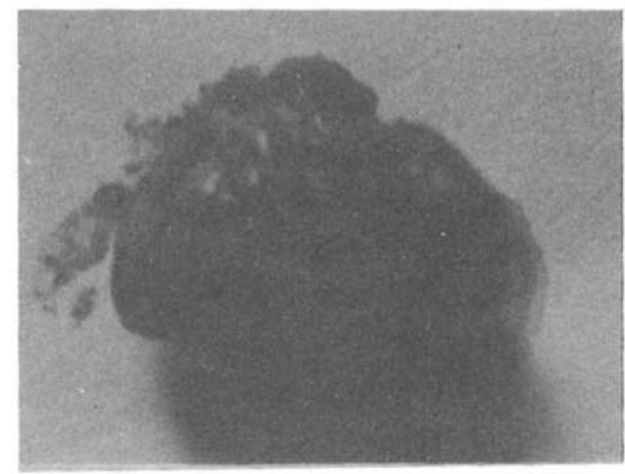

图 2 对照组 21 号肉眼观察照片 $3.2 \mathrm{~g}$ 松散, 表面呈菜花状 $(\times 0.2)$

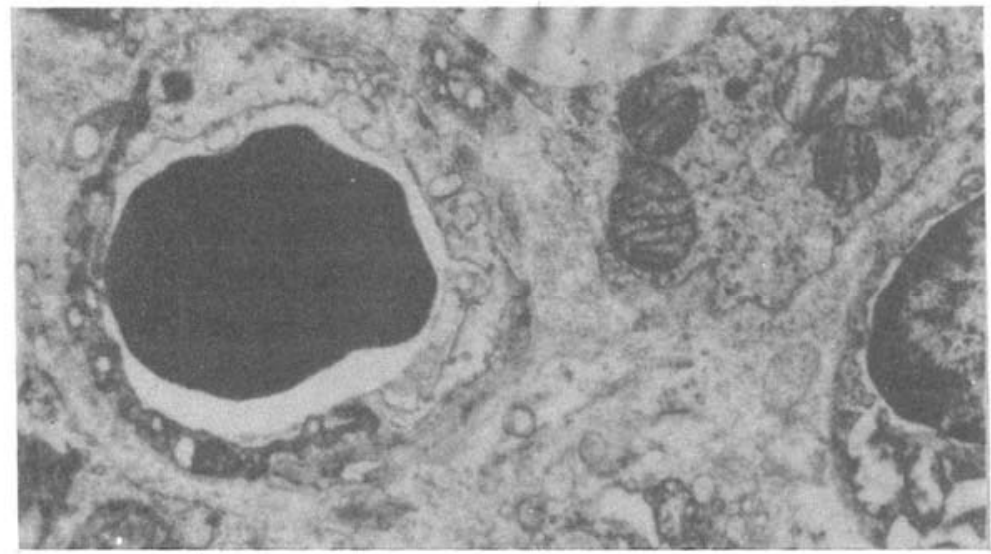

图 3 治疗组 1 号透射电镜观察照片

醄重 $0.5 \mathrm{~g}$, 左方微血管中红细胞萎缩, 右上方肉瘤细胞中线粒体肿胀 $(\times 6200)$

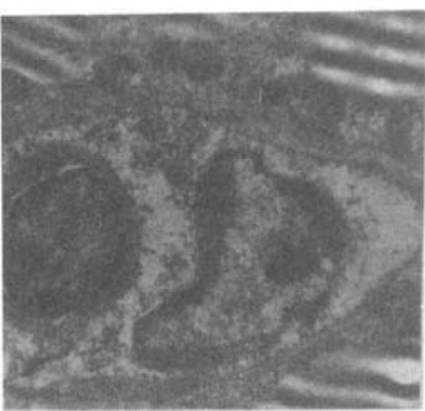

图 4 治疗组 1 号透射电镜观察照片 㢞重 $0.5 \mathrm{~g}$, 左方一免疫细胞表面有足状突起, 已进 入右方一肉瘦细胞中且接近细胞核 $(\times 5000)$

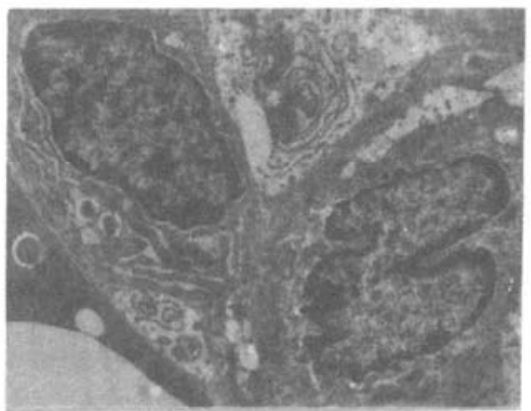

图 5 对照组 15 号透射电镜观察照片 瘤重 $1.5 \mathrm{~g}$, 两相邻生长的肉瘤细胞, 分别有一核, 其中一核异形, 核膜曲折凹陷; 两细胞膜处结合紧 密, 膜界不清 $(\times 2950)$ 


\subsection{Faulgen 染色法测定核 DNA 的倍性}

用同一切片上的淋巴细胞 (二倍体) 定标, 测得淋巴细胞积分光密度 $D_{\mathrm{I} . \mathrm{L}}$. 参数测量前的 定标结果是:

$$
D_{\text {L.L. }}(\text { 磁疗组 })=1.1, \quad D_{\text {LL. } 2}(\text { 对照组 })=0.81 .
$$

根据 $\mathrm{DNA}_{\mathrm{L}}=D_{\mathrm{LC}} / D_{\mathrm{LL}}$ 计算 $\mathrm{DNA}$ 含量. 式中 $D_{\mathrm{L} . \mathrm{C}}$ 是肉瘤细胞的积分光密度, $\mathrm{DNA}_{\mathrm{L}}$ 是 $\mathrm{DNA}$ 光度, 它反映 DNA 含量. 如果 $\mathrm{DNA}_{\mathrm{L}}=N$, 则核中为 $2 N$ 倍体的染色体结构. 结果见表 1 和 $2, p<0.001$. 于是得出 $: \mathrm{DNA}_{\mathrm{L} 1}$ (磁疗组) $=1.38$ (超二倍体) $; \mathrm{DNA}_{\mathrm{L} 2}$ (对照组) $=3.84$ (近八倍 体).

表 1 磁疗组核 DNA 倍性测量 (测量细胞总数:64)

\begin{tabular}{cccc}
\hline 测试项目 & $D_{\mathrm{LI} .1}$ & $D_{\mathrm{LC1}}$ & DNA $_{\mathrm{L} 1}$ \\
\hline 总和 & 70.4 & 97.1 & 88.3 \\
平均值 & 1.1 & 1.52 & 1.38 \\
标准差 & \pm 0.0 & \pm 0.546 & \pm 0.497 \\
\hline
\end{tabular}

表 2 对照组核 DNA 倍性测量(测量细胞总数:61)

\begin{tabular}{cccc}
\hline 测试项目 & $D_{\mathrm{LL} 2}$ & $D_{\mathrm{LC} 2}$ & $\mathrm{DNA}_{\mathrm{L} 2}$ \\
\hline 总和 & 49.2 & 188 & 233 \\
平均值 & 0.807 & 3.08 & .3 .82 \\
标准差 & \pm 0.0 & \pm 1.28 & \pm 1.58 \\
\hline
\end{tabular}

\section{4 细胞结构的体视学分析结果}

根据物体切面上某一成分的平均分面积与这一成分的平均分体积相等, 进行细胞二维计 量参数向三维参数的转化计算. 数据以平均值 \pm 标准差 $(X \pm S D)$ 表示, 见表 3 . 两组均数比 较先行 $F$ 检验, 根据方差齐同与否再进行 $t$ 或 $t^{\prime}$ 检验.

上述数据具体给出, 经磁疗后的肉瘦细胞核形较圆 (核圆球度 $=0.31 \pm 0.01$ ), 核体密度 $(0.35 \pm 0.05)$ 减小, 胞质体密度 $(0.65 \pm 0.05)$ 增大, 从而核质比 $\mathrm{N} / \mathrm{P}$ 减小. 这些说明磁场使 肉㾇细胞的恶性程度降低, 抑制其高速和异形生长。

表 3 肉㾇细胞的二维和三维形态计量参数 ${ }^{\mathrm{a}}$ (单位为 $\mu \mathrm{m}$ 或 $\mu \mathrm{m}^{2}$ )

\begin{tabular}{|c|c|c|c|c|c|c|c|c|}
\hline 组 & 细胞周长 & 细胞轴比 & 细胞异形指数 & 细胞质面积 & 核周长 & 㤥面积 & 核轴比 & 㤥异形指数 \\
\hline \multirow[b]{2}{*}{ 磁疗组 } & 42.04 & 1.42 & 0.87 & 71.73 & 27.52 & 63.29 & 1.55 & 3.54 \\
\hline & \pm 5.60 & \pm 0.13 & \pm 0.05 & \pm 26.71 & \pm 2.84 & \pm 14.02 & \pm 0.21 & $\pm 0.07^{\circ}$ \\
\hline \multirow{2}{*}{ 对䁌组 } & 40.25 & 1.74 & 0.93 & 61.02 & 30.22 & 71.734 & 1.62 & 4.02 \\
\hline & \pm 6.66 & \pm 0.13 & \pm 0.02 & \pm 24.99 & \pm 3.77 & \pm 13.32 & \pm 0.26 & \pm 0.30 \\
\hline 组 & 核圆形度 & 胞质体密度 / \% & 细胞比表面 & 细胞因球度 & 核体密度/\% & 核比表面 & 核圆球度 & 核质比 \\
\hline \multirow{2}{*}{ 疗组 } & 0.94 & 0.65 & 0.48 & 0.27 & 0.35 & 0.61 & 0.31 & 0.53 \\
\hline & $\pm 0.04^{\circ}$ & $\pm 0.05^{*}$ & \pm 0.08 & \pm 0.02 & $\pm 0.05^{\circ}$ & \pm 0.07 & $\pm 0.01^{\circ}$ & $\pm 0.08^{*}$ \\
\hline \multirow{2}{*}{ 对照组 } & 0.82 & 0.59 & 0.46 & 0.30 & 0.41 & 0.56 & 0.28 & 0.69 \\
\hline & \pm 0.06 & \pm 0.07 & \pm 0.07 & \pm 0.04 & \pm 0.07 & \pm 0.04 & \pm 0.01 & \pm 0.06 \\
\hline
\end{tabular}

a) 表中* $p<0.05, * * p<0.01$

\section{3 讨论}

\section{1 磁场影响茜细胞的代谢}

线粒体的主要功能在于通过呼吸作用将食物分解产物中储存的能量逐步释放出来, 供应 细胞各项活动的需要, 故有“细胞动力站”之称. 粗面内质网的重要功能是合成和输运蛋白质. 我们观察到, 经脉冲磁场作用后, 肉瘤细胞内线粒体和粗面内质网由正常变成水肿. 这种形态 
的变异, 说明磁场影响了癌细胞的代谢功能. 另外, 经磁场作用后, 㿋瘤内部微血管较少, 且红 细胞萎缩, 使肉瘤细胞缺乏营养。这和磁场作用后, 肉瘤生长缓慢甚至变小相符合.

\section{2 磁场影响宫细胞的高這和异形生长}

一般认为, 癌细胞的核质比 (N/P)值增大, 核形异常, 具有多个深染的核仁等特性, 表示癌 细胞缺乏明显的分化特征, 与癌细胞的高速生长的特性相对应. N/P 值的测定已成为观家细 胞癌变程度和恶性肿瘤早期诊断的重要标准.

从细胞结构的体枧学统计数字说明, 经磁场作用后, 肉瘦细胞核的形状较圆, 核体密度减 小, 核质比 N/P 减小. 这些都说明磁场使肉瘤细胞恶性程度降低, 其高速和异形生长受到抑 制.

磁场对运动电荷的洛仑兹力使运动带电粒子束缚在拉莫尔半径以内, 会影响带电粒子对 细胞膜和核膜的正常通透性, 从而对肉瘤细胞的高速生长和繇足式浸润产生抑制作用.

\section{3 磁场抑制葆细胞的分裂和 DNA 的台制}

我们用光镜观察到磁场作用后肉瘤细胞的有丝分裂相减少 ${ }^{[8]}$. Faulgen 染色法测量核中 DNA 倍性，观测到磁场作用后降低. 可见，磁场作用可以损伤肉瘦细胞核的 DNA 复制和抑制 癌细胞的有丝分裂.

肉㿔细胞分裂时, 其核内全部成为电子密度高的染色体, 并且由赤道面移到两极, 末期形 成 2 个核. 脉冲磁场产生的随时间变化的电场在细胞范围内, 对空间而言, 可近似规为均匀 的. 均匀电场对带电粒子的电场力大小和方向都相同, 能阻碍一分为二的细胞分裂. 由于肉 瘤细胞核带的电荷多, 分裂速度快, 所以电场能阻碍肉瘤细胞的有丝分裂, 而对正常细胞的影 响较小,

\section{4 磁场提高宿主的细胞免疫功能}

炎性细胞聚集于局部, 发挥对癌瘤的抑制作用,促使癌细胞的解体和坏死. 常表现为癌细 胞内及其周围有数量不等的淋巴细胞、浆细胞浸润, 这就是淋巴细胞、浆细胞反应 (reaction of lymphocytes and plasma 简称 RLP)，近年来，国内外临床实验资料表明: 人类乳癌、胃癌、结肠 癌等恶性肿罍组织中出现 RLP 反应, 这是宿主排斥和预防癌的免痃形态表现 ${ }^{[11,12]}$.

我们用光镜观腺到磁场作用后, 在癌细胞周围的炎性细胞(淋巴细胞、浆细胞、巨噬细胞 等)大量出现的 RLP 反应 ${ }^{[8]}$, 并用透射电镜观察到磁场加强免疫细胞溶癌现象.

免疫是机体对外来的和内部的非已抗原的识别而起反应,通过各种免疫细胞和血液循环 中的各种免疫球蛋白而使宿主获得一种主动性防御 ${ }^{[13]}$. 抗原是指细菌、病毒、非己组织或不 受控制的病细胞. 宿主的控制和瘐瘤的“免疫逃逸”是彼消此长的矛盾双方. 控制和逃逻都和 生物电磁现象密切相关. 国内学者通过实验和临床发现, 磁场能提高淋巴细胞的转化率和电 泳率 ${ }^{[1,14]}$. 我们的实验中发现接近人的生理频率 (1 Hz 左右)的超低频脉冲磁场加强 RLP 现 象和免疫细胞溶癌的能力, 这可能是超低频脉冲磁场发出了发现癌细胞活动的警报, 唤起了免 疫细胞要奋起防御和歼灭癌瘤. 这方面机制的探讨的实验正待进行.

致谢 感谢同济医科大学基础医学院电子显微镜室李统平、病理教研室吴人亮、倪鹃等同 志给予的指导和帮助. 


\section{考文献}

1 本国栋, 周万松, 部立文, 等, 生物磁学—应用、技术、原理. 北京: 国防工业出版社, 1993.89:97 103

2 Halpern M H, Greene A E. Effects of magnetic fields on growth of hela cells in tissure culture. Nature, 1964,4 933:717

3 Mulay I L, Mulay L. N. Effects of a magnetic field on sarcoma 37 ascites tumour cells. Nature, 1961,4 780:1 019

4 张小云,刘标, 张㭲恒,等. 磁场对细胞生长分裂的影响及其机制的探讨. 中国科学, B 输, 1989, (2):164

5 常汉英, 李桂兰, 潘玉明, 等. 磁场对鼠 S-180 肉䚀影响的实验观腺。中华物理医学杂志, 1985,7(3):169

6 常汉英, 本桂兰. 汪国珠. 磁场疗法治疗苾性肿㿑 18 例初步报告. 见: 生物医学物理研究. 武汉: 武汉大学出版社. 1990.74

7 周万松. 场治疗肿的的应用进展. 中华生物磁学, 1994, 8(2):1

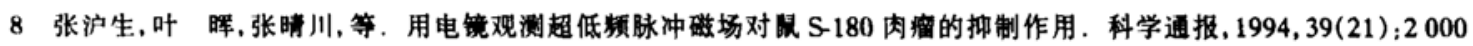

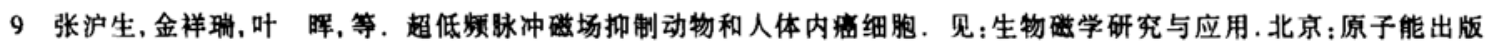
社, 1994.18

10 申 洪. 三维形状因子一一球度计算方法研究. 中华物理医学杂志, 1992, 14(1):39

11 Shimokawara L. Imamura M, Yamanaka N. Identification of lymphocyts subpopulations in human breast cancer tissure and its significance. Cancer, 1982,49:1456

12 Bennet S H, Futrell J W, Roth J A. Prognostic significance of histologic host response in cancer of the larynx or hypolarynx. Cancer, 1971, 28:1255

13 皮尔斯 G B. 瘦———发育生物学问题. 北京: 科学出版社, 1981

14 陈延生, 咯敏黄, 金兴梅, 等. 磁场对血液流变学的影响. 见: 生物医学物理研究. 北京: 原子能出版杜, 1992.25 